\title{
Combatting illicit tobacco trade: What is the role of EU law enforcement training?
}

\author{
Detlef Schröder', Gábor Bóta', Maria Molina Sierra ${ }^{1}$
}

Tobacco's illicit production and trade pose a serious threat to public health, citizen safety, and, to some extent, national security. This criminal phenomenon undermines governments' control efforts and anti-smoking strategies to dissuade consumption, by increasing access to tobacco products, made available in the black market at lower prices to young generations or resource-poor individuals. The awareness of illegal cigarette trade as a practice driven by international crime networks and source of hearty revenues goes along with the recognition that illicit tobacco trade is a global problem, which requires cooperation on a worldwide scale.

Together with the European Commission, EU countries are active partners in the WHO Framework Convention on Tobacco Control (FCTC) and signatories of the Protocol to Eliminate Illicit Trade in Tobacco Products ${ }^{1}$, an international treaty designed to combat the worldwide illicit tobacco trade.

To this purpose, the European Union institutions and its Member States have developed effective law enforcement instruments and mechanisms to fight against tobacco illicit manufacturing and smuggling practices. The European Union Agency for Law Enforcement Training (CEPOL) a contributes to these efforts by providing EU-wide training to law enforcement officials dealing with tobacco fraud-related investigations and operations.

Each year around 500 police and customs officers receive CEPOL training on contemporary tobacco crime typologies, innovative intelligence-tools and excise-fraud investigative techniques. CEPOL training and learning actions in this field are catering for contemporary relevant training needs of law enforcement, with a particular focus on the following aspects:

- Illegal production of cigarettes within the European Union;

- Contraband of 'illicit whites ${ }^{\mathrm{b}}$ via the Eastern borders of the European Union;

- Maritime smuggling of cigarettes;

- Integration of financial investigations into cigarette cases;

- Cooperation tools related to serious organized crime investigations.

These training activities are organized in the framework of the European Multidisciplinary Platform Against Criminal Threats (EMPACT) ${ }^{\mathrm{c}}$ under the European Union crime priority 'Excise Fraud'.

One of the most worrying trends of excise fraud is the growing prevalence of illegal cigarette production in the European Union. A couple of years ago, it was rare to detect production sites in EU countries; today, this is quite a regular incident. The concerned crime-groups are typically multinational and,
AFFILIATION

1 European Union Agency for Law Enforcement Training (CEPOL), Budapest, Hungary

\section{CORRESPONDENCE TO}

Detlef Schröder. Executive Director, European Union Agency for Law Enforcement Training (CEPOL), Pf. 314, 1903, Budapest, Hungary. E-mail: info@cepol.europa.eu

\section{KEYWORDS}

CEPOL, European Union (EU), law enforcement, training, capacitybuilding

Received: 12 February 2021 Accepted: 21 February 2021 
functionally, highly specialized. They organize the whole range of production, wholesale, transport and retail of illegally produced tobacco goods just like any globally active corporation. Organized crime groups typically set up production sites in warehouses in remote areas, use security installations and isolate the workers of illegal status - usually arriving from non-EU, neighborhood countries. Production and storage sites are often placed in other countries than the point-of-sale to minimize the suspicion of local law enforcement forces and the loss of profit in case of detection.

Apart from the use of regular intelligence and enforcement toolsets, critical issues for detection are: monitoring the trade of production machines, the trade of precursors, and the movement of known criminals and workers employed in illegal factories.

The smuggling of cheap, original cigarettes (illicit whites) from Eastern European countries (e.g. Belarus, Ukraine, Moldova, Russia) and the contraband of tobacco products via sea containers are traditional, common threats. Most of the time, the cigarettes are concealed in cover loads and smuggled into EU countries, hidden in the vast amount of legitimate trade. Effective customs' risk assessments and profiling systems are crucial elements for detection. International training activities discuss the effective use of mobile units' control, anti-corruption measures and new techniques regarding the land and maritime border control, such as the operation of modern scanners and satellite-based surveillance systems.

Just like any other organized crime, illicit cigarette trade and manufacturing are committed to profit. The arrest and incarceration of perpetrators, and the seizure of illegally manufactured cigarettes and related production equipment, are necessary and relevant measures. However, the ultimate deterrence is the confiscation of criminal proceeds, like the seizure of villas, luxury cars, and other investments. With this in mind, CEPOL focuses on raising awareness on the international asset recovery possibilities and good practices on financial investigations. The growing capacity of law enforcement authorities in financial investigations is commendable - but there is still room for improvement. Innovations related to technological development, such as new type of payment providers or the emergence of virtual currencies, increase the complexity of investigations and make it harder to disrupt the supply of illicit tobacco smuggling and preceding manufacturing activities.

CEPOL training activities emphasize how intelligence and evidence can be shared in cross-border investigations. Nevertheless, tackling the scourge of illegal tobacco production and trade can only be done efficiently if the Member States fully exploit all available law enforcement and judicial cooperation structures such as CEPOL, Europol ${ }^{\mathrm{d}}$ and Eurojust ${ }^{\mathrm{e}}$. By facilitating cooperation through mutual assistance and knowledge sharing among law enforcement officials in Europe, we will contribute to eradicating illicit tobacco and curb this major threat to public health.

d Europol is the European Union Agency for Law Enforcement Cooperation, which is governed by Regulation (EU) 2016/794 of the European Parliament and of the Council of 11 May 2016 on the European Union Agency for Law Enforcement Cooperation (Europol) and replacing and repealing Council Decisions 2009/371/JHA, 2009/934/JHA, 2009/935/JHA, 2009/936/JHA and 2009/968/JHA.

e Eurojust stands for European Union Agency for Criminal Justice Cooperation, which is governed by Regulation (EU) 2018/1727 of 14 November 2018 on the European Union Agency for Criminal Justice Cooperation (Eurojust).

To participate in online CEPOL training activities, law enforcement officials must be registered users of CEPOL's online learning platform, LEEd. A valid LEEd account provides access to a full range of learning resources, including online learning modules, platforms of communities of practice, webinar resources and access to the repository of professional e-Journals and e-books. To apply to residential or other type of CEPOL training activities, law enforcement officials should visit the agency's website at https://www.cepol.europa.eu/ education-training/our-approach/how-to-apply.

\section{REFERENCES}

1. WHO Framework Convention on Tobacco Control. The Protocol to Eliminate Illicit Trade in Tobacco Products. World Health Organization; 2013. Accessed February 12, 2021. https://apps.who.int/iris/bitstream/ handle/10665/80873/9789241505246_eng.pdf; jsessionid=BBAC04F4B2BDA25EA6DA1A9112615704? sequence $=1$

\section{CONFLICTS OF INTEREST}

The authors have completed and submitted the ICMJE Form for Disclosure of Potential Conflicts of Interest and none was reported.

\section{FUNDING}

There was no source of funding for this research.

PROVENANCE AND PEER REVIEW

Commissioned; internally peer reviewed. 